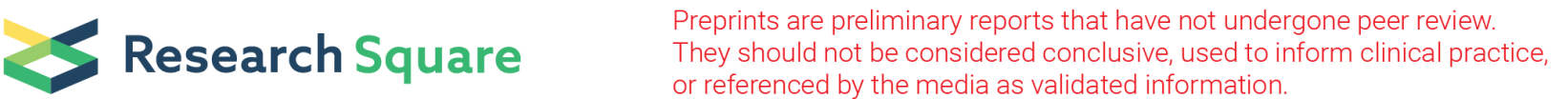 \\ The impact of incorrect registration on survival rate of children with very rare tumors
}

\section{Lukas Salasevicius}

Vilniaus universitetas Medicinos fakultetas

\section{Giedre Rutkauskiene}

Lietuvos sveikatos mokslu universitetas Medicinos fakultetas

\section{leva Vincerzevskiene}

Nacionalinis vezio institutas

Jelena Rascon ( $\nabla$ jelena.rascon@gmail.com )

Vilnius University Hospital Santaros Klinikos https://orcid.org/0000-0003-4420-6943

\section{Research}

Keywords: very rare tumors, children, survival, registry

Posted Date: December 12th, 2019

DOI: https://doi.org/10.21203/rs.2.18881/v1

License: (c) (i) This work is licensed under a Creative Commons Attribution 4.0 International License.

Read Full License

Version of Record: A version of this preprint was published at Scientific Reports on July 7th, 2021. See the published version at https://doi.org/10.1038/s41598-021-93670-2. 


\section{Abstract}

Background: Pediatric very rare tumors (VRTs) represent a heterogeneous subset of childhood malignancies, with reliable survival rate estimations depending dramatically on each (un)registered case. The current study aimed to evaluate the number of VRTs among Lithuanian children and the change in treatment outcome over the 16 year study period as well as to assess the impact of the registration status on survival estimation. Methods. We performed a population-based retrospective analysis across children below 18 years old diagnosed with VRTs in Lithuania between the years 2000 to 2015. The identified cases were then crosschecked with the Lithuanian Cancer Registry (a population-based epidemiology cancer registry) for the registration and survival status. A five year overall survival (OS 5y ) was calculated using Kaplan-Meier estimation method. Results . Forty-four children affected by VRTs were identified within the defined time frame. Nine of them (20.5\%) were not reported to the Lithuanian Cancer Registry at the time of diagnosis. The OS $5 y$ of the entire cohort was $55.8 \%$. The cure rate did not improve over the analyzed time periods $-54.2 \%$ in $2000-2007$ vs $49.4 \%$ in $2008-2015$. The OS $5 y$ differed significantly between registered $(n=35)$ and unregistered $(n=9)$ cohorts: $45.1 \%$ vs $100 \%$, respectively $(p=0.016)$. The tumor progression was responsible for treatment failure in $95 \%$ of cases. Conclusions. The OS $5 y$ of all analyzed children affected by VRT was lower as compared to the other childhood cancers. The survival rate of the unregistered patients was significantly superior that mislead interpretation of treatment outcome. Meticulous registration of VRTs is crucial for correct evaluation of treatment outcome, especially across small countries with fewer numbers of cases.

\section{Introduction}

Malignant tumors in children are very rare: a recently calculated incidence of pediatric cancer in childhood was 155.8 cases per million children between the ages of 0 to 19 years (1). Although infrequent, the vast majority of pediatric cancers can be treated in international clinical trials or following treatment guidelines developed by expert groups. Despite the well-elaborated management strategies for the most common childhood malignancies, childhood cancer remains the second leading cause of illness-related mortality among children in developed countries (2).

Pediatric very rare tumors (VRTs) represent a particular subset of childhood cancers, comprising approximately 9 to $11 \%$ of all malignancies occurring in children below the age of $20,75 \%$ of them diagnosed between the ages of 15 to 19 years old $(3,4)$. The European Cooperative Study Group for Pediatric Rare Tumors (EXPeRT) defines a VRT as any solid malignancy or borderline tumor that has an incidence rate of $\leq 2$ per million per year and/or is not considered for treatment in clinical trials (5). As a result, VRTs pose a real diagnostic and therapeutic challenge due to their rarity and lack of international treatment guidelines or ongoing clinical trials.

The overall survival rates of childhood cancer differ across European countries. Data collected from a EUROCARE5 study demonstrated that $20-30 \%$ of children treated in Eastern Europe between 2000 and 2007 have lower overall survival rates than children treated in Western Europe (6-8). In particular, cure 
rates in Lithuanian patients were approximately $10-20 \%$ lower compared to the average European figures. Apart of previously existed inequalities of childhood cancer care, incomplete registration of relatively uncomplicated cancer cases (mostly local tumors that can be safely managed by effective surgery and have favorable outcomes) could contribute to the reported inferior survival rates. Our previous pilot study focused on the tumors of the central nervous system (CNS) revealed that up to $27 \%$ of cases were not registered in the Lithuanian Cancer Registry (LCR) (9). Based on this observation, we initiated the current population-based study that aimed to evaluate the number of VRTs in Lithuanian children and to verify their registration status in the LCR as a potential predictive factor of the treatment outcome.

\section{Material And Methods}

Study population and design

We performed a retrospective population-based study of children diagnosed and treated for VRTs in Lithuania between 2000 and 2015. A VRT was defined as described by the International EXPeRT Cooperative Group (see above) (5). Pediatric age was considered as less than 18 years of age at the time of the diagnosis.

The institutional databases of both Lithuanian Pediatric Oncology Centers at Vilnius University Santaros Klinikos (VUHSK) and Hospital of Lithuanian University of Health Sciences Kaunas Clinics (LUHSKK) were reviewed to identify VRTs as defined previously. Thereafter, the retrieved cases were compared with the LCR database to verify patients' registration and survival status and calculate survival rates.

Baseline characteristics were collected either electronically through institutional databases, or manually through paper records. The primary end point to assess treatment outcome was defined as an overall survival at five years after diagnosis $\left(\mathrm{OS}_{5 y}\right)$. In order to evaluate changes in the survival rates over the 16year time period the entire cohort was split into two groups according to the time of treatment: between 2000 and 2007 as well as 2008 and 2015. Ultimately, the OS $_{5 y}$ was compared between registered and unregistered patients.

The vital status of the study group was assessed on March 1, 2017. A passive follow-up approach was applied based on the data registered at LCR - a population-based cancer registry collecting personal and demographic data as well as disease-related information (cancer site, date of diagnosis, method of cancer verification) and vital status (if appropriate - date and cause of death) of all cancer patients in Lithuania including children.

\section{Statistical analysis}

The descriptive statistics methods were used for continuous variables. Estimates of OS were calculated using Kaplan-Meier method. Death of any cause at any time was defined as an event to estimate the probability of OS. The results were considered statistically significant when $p$ value was $<0.05$. The 
statistical analysis was performed using IBM SPSS Statistics 23.0 software. The data were evaluated on March 2017.

\section{Results}

\section{Patients' characteristics}

A total of 44 children with an identified VRT were diagnosed and treated for between the years 2000 to 2015 in Lithuania. A median of two new cases per year were documented ranging from 0 to 7 (refer to Table 1 for baseline characteristics). The median age at the time of their diagnosis was 12 (range $0-17$ ) years with a slight female predominance $(n=27 ; 61.4 \%)$. The distribution of histologic types amongst the study subjects is depicted in Fig. 1. Overall, 23 histologic tumor types were identified: adrenocortical carcinoma was the most frequent one $(n=7 ; 15.9 \%)$, followed by hemangioendothelioma $(n=4 ; 9.1 \%)$, renal/thyroid carcinomas and rhabdoid tumors ( $n=3,6.8 \%$ each). There were two cases of pheochromocytoma, gastric adenocarcinoma, salivary gland carcinomas, hemangioblastoma, inflammatory myofibroblastic tumors, and ovarian cancers (4.5\%) and 12 single cases of different tumor types (Fig. 1). Most patients $(n=39 ; 88.6 \%)$ presented with localized tumors at the time of diagnosis, half of them remained in complete remission at the time of evaluation. Tumor progression compromised the cure in $47.7 \%$ of cases, one patient $(2.3 \%)$ deceased due to toxic complications. 
Table 1

Baseline characteristics of the study patients $(n=44)$

\begin{tabular}{|c|c|}
\hline & Number of patients (\%) [IQR] \\
\hline Years at diagnosis, median (min-max) [IQR] & $12(0-17)[6-15]$ \\
\hline $\begin{array}{l}\text { Gender } \\
\text { Boys } \\
\text { Girls }\end{array}$ & $\begin{array}{l}17(38.6) \\
27(61.4)\end{array}$ \\
\hline $\begin{array}{l}\text { Disease spread at diagnosis } \\
\text { Metastatic } \\
\text { Local }\end{array}$ & $\begin{array}{l}5(11.4) \\
39(88.6)\end{array}$ \\
\hline $\begin{array}{l}\text { Survival status } \\
\text { Alive in remission } \\
\text { Dead due to disease relapse / progression } \\
\text { Treatment-related mortality }\end{array}$ & $\begin{array}{l}22(50) \\
21(47.7) \\
1(2.3)\end{array}$ \\
\hline $\begin{array}{l}\text { Registration status at the LCR } \\
\text { Registered } \\
\text { Unregistered }\end{array}$ & $\begin{array}{l}35(79.5) \\
9(20.5)\end{array}$ \\
\hline $\begin{array}{l}\text { Treating center } \\
\text { Vilnius } \\
\text { Kaunas }\end{array}$ & $\begin{array}{l}26(59.1) \\
18(40.9)\end{array}$ \\
\hline $\begin{array}{l}\text { Follow-up, median years from diagnosis (min-max) [IQR] } \\
\text { All patient }(n=22) \\
\text { Registered }(n=14) \\
\text { Unregistered }(n=8) \\
\text { Treated in } 2000-2007(n=11) \\
\text { Treated in 2008-2015 }(n=11)\end{array}$ & $\begin{array}{l}9.6(1.5-16.6)[4.5-11] \\
9.9(3.1-16.6)[6.0-12.3] \\
8.4(1.5-11.8)[3.6-10.6] \\
11.0(9.4-16.6)[10.5-12.8] \\
4.6(1.5-9.6)[3.3-7.3]\end{array}$ \\
\hline Abbreviations. IQR: $25-75 \%$ interquartile range; LCR: Lith & anian Cancer Registry. \\
\hline
\end{tabular}

Registration at the Lithuanian Cancer Registry

The data verification with the LCR revealed that nine of 44 patients $(20.5 \%)$ were not registered at the time of diagnosis (Fig. 1). Eight of nine missing patients (88.9\%) were diagnosed at LUHSKK and comprised $44.4 \%(8 / 18)$ of all identified pediatric VRTs treated at the center as compared to $3.8 \%(1 / 26)$ of patients treated at VUHSK. The most common types of non-reported cases were salivary gland carcinoma, inflammatory myofibroblastic tumor and thyroid carcinoma (2 cases each), followed by single cases of adrenocortical carcinoma, hemangioblastoma and carcinoma of the uterus (Fig. 1).

Treatment outcome

The $\mathrm{OS}_{5 y}$ of the entire cohort was $55.8 \%$. Surprisingly, the cure rate did not improve over the analyzed time periods $-54.2 \%$ in $2000-2007$ vs $49.4 \%$ in $2008-2015$ (Fig. 2a). The median follow-up time of the compared patients' groups was 11.0 and 4.6 years, respectively (Table 1). In line with our expectations the $\mathrm{OS}_{5 y}$ rate of the unregistered patients was significantly higher than that of the registered cohort - 
$100 \%$ vs $45.1 \%$ ( $p=0.016$ ) (Fig. $2 b$ ) with similar median follow-up time of 8.4 and 9.9 years, respectively (Table 1). The difference in OS rates remained detectable 10 years after the diagnosis accounting for $80 \%$ in the unregistered cohort as compared to $45.1 \%$ in the registered one (Fig. 2 b).

\section{Discussion}

Our study aimed to address epidemiological data of pediatric VRTs in Lithuania - a small country of 2.92 million inhabitants, 524.5 thousand of which comprise the population of interest, namely children below 18 years of age (as reported in 2015, www.stat.gov). Overall, 44 VRT cases of 23 different histological subtypes were identified within 16 years with the median of two new cases per year. This means that each Lithuanian pediatric oncology center encountered one new VRT case per year. The main drawback of our population-based study was its retrospective nature that did not allow us to verify relevant parameters (e.g. details on adverse events, treatment etc.) due to limited data source availability. Nevertheless, we were able to demonstrate that the survival of VRTs in children was inferior $(55.8 \%$ in total) as compared to the average $80 \%$ cure rate of pediatric malignancies. Similar results were reported in adults by population-based analysis of the Surveillance of Rare Cancers in Europe (EUROCARE) project (10) - with rare cancers displaying lower survival rate (47\%) than the common cancers $(65 \%)$. The scarce expertise due to rarity of cases and absence of clinical trials were main contributors to the inferior survival.

The lack of improvement in cure rate over time (54.2\% in $2000-2007$ vs $49.4 \%$ in $2008-2015)$ was rather unexpected. National population-based studies in leukemia $(11,12)$ and single-center reports in solid tumors (13-15) demonstrated significant improvement in overall survival over the last two decades. The main reason of treatment failure in VRTs was progressive malignancy: $95 \%$ of deaths (in 21 out of 22 cases) occurred due to tumor relapse or progression. Drug-resistant cancers remain the main challenge for pediatric oncology community in Europe as demonstrated by the population-based EUROCARE-5 study that reported no significant change in mortality for lymphoma and most common pediatric nonVRT childhood cancers in 1999-2007 (6). Thus, expanding national, regional and international collaboration with a special focus on VRTs is crucial to overcome incurable cancers.

As expected, the survival rate of unregistered patients was higher than the one of the registered patients ( $100 \%$ vs $45.1 \%$ at 5 years). The difference remained significant for at least 10 years after diagnosis. Given the extreme rarity of VRTs, accurate reporting to cancer registries is crucial for reliable calculation of treatment outcome. Insufficient registration of pediatric cancers was confirmed in more common childhood cancers, e. g. for CNS tumors - the study that analyzed survival of European children based on the national population-based cancer registry data highlighted incomplete registration of non-malignant entities in many countries and, as a consequence, a lower overall survival (7). The recent survey focused on the rate of pleuropulmonary blastoma in Europe also demonstrated lower than estimated number of reported cases in Eastern / Central European countries (16). 
A high rate of unregistered tumors in our study (20.5\%) could be partially underpinned by an inconsistency in the national regulatory requirements: there was a formal obligation for health care providers to report every new cancer case to the cancer registry, however the legal status registry was not accordingly formalized. This resulted in different interpretation of the reporting obligation and restriction data flow. The majority of the unregistered cases (88.9\%) came from one of two pediatric oncology centers and reflected institutional policy with regard to the obligation to report new cancer cases to the LCR. All the missing data identified during this study were entered retrospectively and included death certificate only.

An additional contributing factor to the high proportion of unreported cases could be insufficient awareness of surgeons, who used to be the first to encounter a VRT in children and adolescents, about the importance of meticulous registration of every pediatric cancer case. In our study most of the tumors (88.6\%) were localized at the time of diagnosis and did not required adjuvant chemotherapy subject complete tumor resection. Therefore, presumably pediatric oncologists were not involved in the patient care of at the initial stage. Several studies have shown that multidisciplinary teamwork affects the diagnosis, management and quality of care in cancer patients $(17,18)$, thus regular tumor boards, including virtual tumor boards as well as international collaborations, should be regarded as a standard of care in the management of childhood cancers $(19,20)$. Improvement in multidisciplinary collaboration between pediatric oncologist, surgeons, and other specialists could increase the registration rate.

Our results clearly demonstrated that timely (not retrospective) and complete registration must be ensured for accurate statistical analysis and data evaluation. In addition to mandatory national reporting regulations, an ongoing European PARTNER (Pediatric Rare Tumor Network - European Registry) project supported by the European Reference Network for Paediatric Cancer aims to create a pan-European system that should enhance international communications between members of the European Union by combining national registries focused on VRTs and creating registries for countries that do not have one, as well as linking these registries with virtual consultation systems (https://webgate.ec.europa.eu). The undertaken action could strengthen registration at the national level. It could be further improved by seeking an agreement on the entities to be registered, especially those of low-grade histology, as an absence of uniform guidelines defining registration of benign CNS tumors resulted in inequalities of survival rate across European countries (7). In our study we identified two cases of non-malignant inflammatory myofibroblastic tumor that is currently not defined as a VRT and not reported to the cancer registries (21). However, both affected patients underwent multiple surgical interventions resulting in almost mutilating late sequelae. Therefore, a revision of the registration criteria for some tumor entities should be considered.

\section{Conclusions}

Incomplete registration of VRTs in cancer registry is an important issue and can significantly affect epidemiologic and outcome data. Regular verification of the pediatric cancer cases could ensure data quality and completeness of registration. Based on our results we would strongly advocate for an active 
collaboration between pediatric oncology centers and national cancer registries to prevent dramatic deviation in statistical analysis and calculation of survival data.

\section{Abbreviations}

CNS: Central nervous system; ExPeRT: European Cooperative Study Group for Pediatric Rare Tumours; LCR: Lithuanian Cancer Registry; LUHSKK: Lithuanian University of Health Sciences Kaunas Klinikos; $\mathrm{OS}_{5 y}$ : Overall Survival at 5 years; VRT: Very Rare Tumor; VUHSK: Vilnius University Hospital Santaros Klinikos

\section{Declarations}

\section{Ethics approval and consent to participate}

All procedures performed in studies involving human participants were in accordance with the ethical standards of the institutional and national research committee and with the 1964 Helsinki declaration and its later amendments or comparable ethical standards. The study was approved by the Vilnius Regional Committee of Biomedical Research (Approval No. 2019/10-1155-646) and Kaunas Regional Biomedical Research Ethics Committee (Approval No. BE-2-86). An informed consent was obtained from individual participants subject they are alive and followed up. If deceased or lost for follow-up, a waiver of informed consent was granted.

\section{Consent for publication}

Not applicable

\section{Availability of data}

The datasets generated and analyzed during the current study are not publicly available due to data protection and privacy but are available from the corresponding author on reasonable request.

\section{Competing interests}

The authors declare that they have no competing interests.

\section{Funding}


The study did no dedicated funding,

\section{Authors' contributions}

LS analyzed the data and wrote the manuscript and revised, GR, IV and JR collected, retrieved and analyzed the data, JR conceptualized and supervised the study. All authors contributed to the study conception, critically revised the manuscript, agreed and approved the final version for submission.

\section{Acknowledgements}

Not applicable

\section{References}

1. Steliarova-Foucher E, Colombet M, Ries LAG, Moreno F, Dolya A, Bray F, et al. International incidence of childhood cancer, 2001-10: a population-based registry study. The Lancet Oncology. 2017;18(6):719-31.

2. Siegel RL, Miller KD, Jemal A. Cancer Statistics, 2017. CA: a cancer journal for clinicians. 2017;67(1):7-30.

3. Kotecha RS, Kees UR, Cole CH, Gottardo NG. Rare childhood cancers-an increasing entity requiring the need for global consensus and collaboration. Cancer medicine. 2015;4(6):819-24.

4. Pappo AS, Furman WL, Schultz KA, Ferrari A, Helman L, Krailo MD. Rare Tumors in Children: Progress Through Collaboration. Journal of clinical oncology : official journal of the American Society of Clinical Oncology. 2015;33(27):3047-54.

5. Bisogno G, Ferrari A, Bien E, Brecht IB, Brennan B, Cecchetto G, et al. Rare cancers in children - The EXPeRT Initiative: a report from the European Cooperative Study Group on Pediatric Rare Tumors. Klinische Padiatrie. 2012;224(6):416-20.

6. Gatta G, Botta L, Rossi S, Aareleid T, Bielska-Lasota M, Clavel J, et al. Childhood cancer survival in Europe 1999-2007: results of EUROCARE-5--a population-based study. The Lancet Oncology. 2014;15(1):35-47.

7. Gatta G, Peris-Bonet R, Visser O, Stiller C, Marcos-Gragera R, Sanchez MJ, et al. Geographical variability in survival of European children with central nervous system tumours. European journal of cancer. 2017;82:137-48.

8. Bonaventure A, Harewood R, Stiller CA, Gatta G, Clavel J, Stefan DC, et al. Worldwide comparison of survival from childhood leukaemia for 1995-2009, by subtype, age, and sex (CONCORD-2): a population-based study of individual data for 89828 children from 198 registries in 53 countries. The Lancet Haematology. 2017;4(5):e202-e17. 
9. Salasevicius L, Pociute K, Rutkauskaite V, Raugalas R, Vincerzevskiene I, Rutkauskiene G, et al. Imact of correct registration of pediatric CNS tumors on assessment of treatment outcome. NOPHO 36th Annual meeting 2018, Vilnius, Lithuania. 2018:118.

10. Gatta G, van der Zwan JM, Casali PG, Siesling S, Dei Tos AP, Kunkler I, et al. Rare cancers are not so rare: the rare cancer burden in Europe. European journal of cancer. 2011;47(17):2493-511.

11. Vaitkeviciene G, Matuzeviciene R, Stoskus M, Zvirblis T, Rageliene L, Schmiegelow K. Cure rates of childhood acute lymphoblastic leukemia in Lithuania and the benefit of joining international treatment protocol. Medicina. 2014;50(1):28-36.

12. Kairiene I, Pasauliene R, Lipunova N, Vaitkeviciene G, Rageliene L, Rascon J. Improved outcome of childhood acute myeloid leukemia in an Eastern European country: Lithuanian experience. European journal of pediatrics. 2017;176(10):1329-37.

13. Juskaite A, Tamuliene I, Rascon J. Results of neuroblastoma treatment in Lithuania: a single centre experience. Acta medica Lituanica. 2017;24(2):128-37.

14. Jakutis G, Rageliene L, Rascon J. Survival of children treated for Ewing sarcoma in Lithuania: a single centre experience. Acta medica Lituanica. 2017;24(4):199-208.

15. Rancelyte M, Nemaniene R, Rageliene L, Rascon J. Wilms tumour in children: 18 years of experience at Vilnius University Hospital Santaros Klinikos, Lithuania. Acta medica Lituanica. 2019;26(2):12533.

16. Tagarelli A, Orbach D, Lopez R, Ami T, Pourtsidis A, Bien E, et al. Are very rare tumours correctly recognized? A European survey on pleuropulmonary blastoma. Abstracts From the 49th Congress of the International Society of Paediatric Oncology (SIOP) Washington, DC, USA October 12-15, 2017. Pediatric blood \& cancer. 2017;64(S3).

17. Brar SS, Hong NL, Wright FC. Multidisciplinary cancer care: does it improve outcomes? Journal of surgical oncology. 2014;110(5):494-9.

18. Hong NJ, Wright FC, Gagliardi AR, Paszat LF. Examining the potential relationship between multidisciplinary cancer care and patient survival: an international literature review. Journal of surgical oncology. 2010;102(2):125-34.

19. Kowalczyk JR, Samardakiewicz M, Fitzgerald E, Essiaf S, Ladenstein R, Vassal G, et al. Towards reducing inequalities: European Standards of Care for Children with Cancer. European journal of cancer. 2014;50(3):481-5.

20. Juan Ribelles A, Berlanga P, Schreier G, Nitzlnader M, Brunmair B, Castel V, et al. Survey on paediatric tumour boards in Europe: current situation and results from the ExPo-r-Net project. Clinical \& translational oncology : official publication of the Federation of Spanish Oncology Societies and of the National Cancer Institute of Mexico. 2018;20(8):1046-52.

21. Ferrari A, Brecht IB, Gatta G, Schneider DT, Orbach D, Cecchetto G, et al. Defining and listing very rare cancers of paediatric age: consensus of the Joint Action on Rare Cancers in cooperation with the European Cooperative Study Group for Pediatric Rare Tumors. European journal of cancer. 2019;110:120-6. 


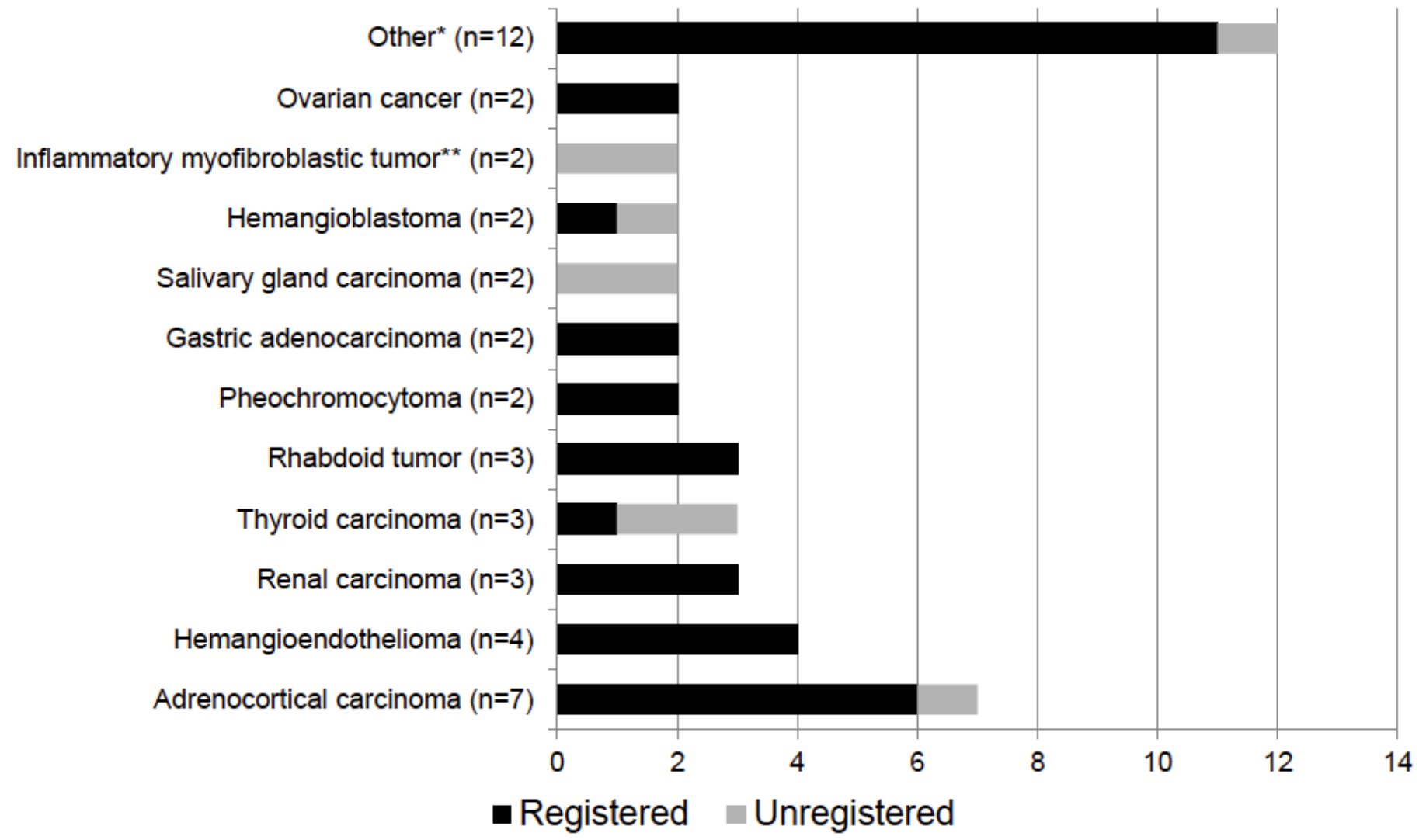

Figure 1

Distribution of histologic types.

a

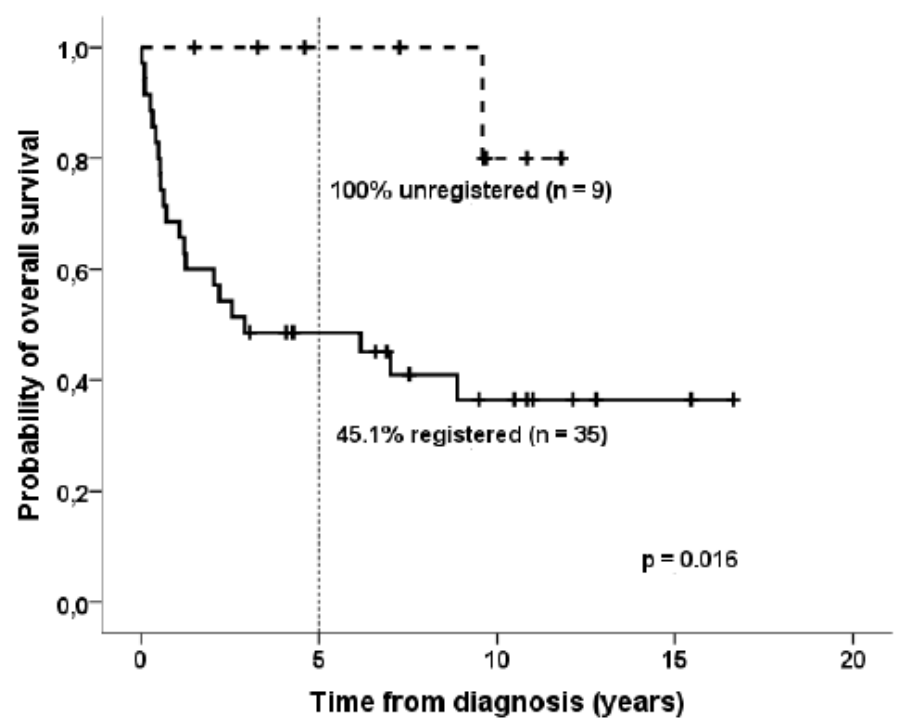

b

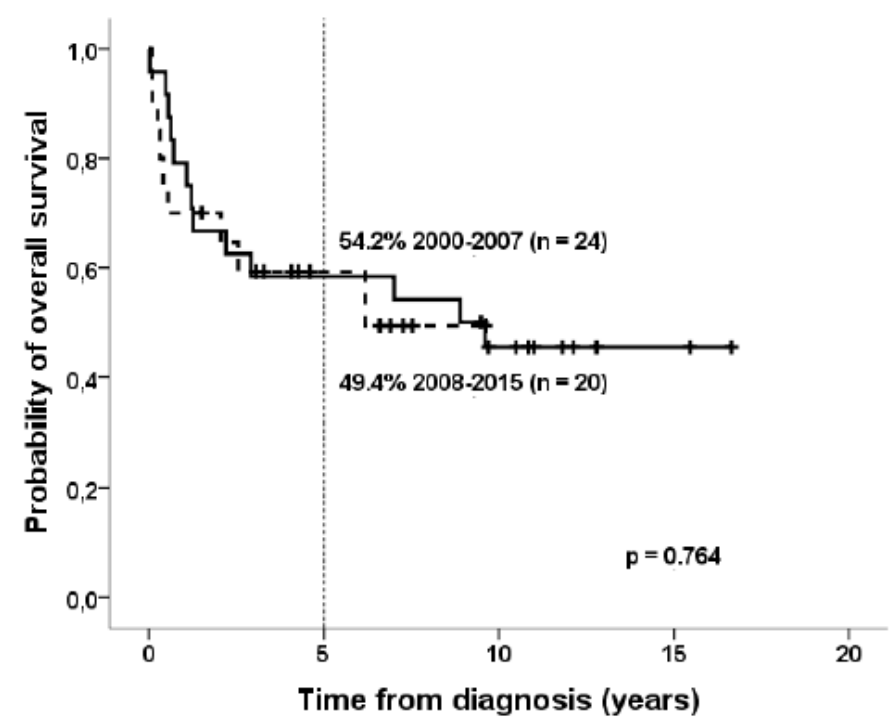


Figure 2

Comparison of five-year overall survival according to: a diagnosis and treatment period; $b$ registration status. 